\title{
Seroprevalence of dengue infection: A hospital based study from Udaipur, Rajasthan
}

\author{
Pragnesh Patel ${ }^{1}$, Ritu Bhatnaga ${ }^{2, *}$
}

Assistant Professor, Dept. of Microbiology, Pacific Medical College and Hospital, Udaipur, Rajasthan, India

*Corresponding Author:

Email: ritub308@yahoo.com

\begin{abstract}
Dengue is one of the most important arthropod- borne viral infections, widely distributed throughout the tropics and subtropics. It is endemic to the Indian subcontinent and associated with explosive urban epidemics and has become a major public health problem in India. The present study was conducted to detect prevalence of Dengue virus infection in Udaipur, Rajasthan.

Materials and Methods: Serum samples from 640 patients clinically suspected of having dengue infection visiting a tertiary care hospital during the period of August 2016 to February 2018 were screened for the presence of Dengue NS1 antigen and IgM and IgG antibodies using one-step immune-chromatographic assay (Dengue Rapid IgM/IgG test and NS1 test by SD BIOLINE).

Result: Out of 640 samples 62 samples $(9.68 \%)$ were positive for Dengue virus infection. Out of total positive Sample for dengue virus infection, $61 \%$ samples were of male patients and $39 \%$ samples were from female patients. Among them $28 \%$ positive samples were from paediatric age group (Age 1- 14 years) and rest were from Adult age group. Seasonal trend showed a gradual increase in Dengue positives starting from August with a peak in October. Most common presentation was fever (98\%).

Conclusion: Number of dengue cases is on increase in the region and continued surveillance is essential to determine epidemiological and seasonal trend.
\end{abstract}

\section{Introduction}

Dengue virus is a positive strand RNA of flaviviridae family with 4 different serotypes and is transmitted to humans by several species of the Aedes mosquito. ${ }^{1}$ The dengue is widely distributed throughout the tropics and subtropics. The term "break bone fever" was coined during the Philadelphia epidemic in 1780. Dengue fever is clinically similar to the illness caused by chickungunya and O'nyongnyong syrup. Dengue has been increasing worldwide over the last few decades and today ranks as the most important vectorborne disease, with about 2.5 billion people in 200 countries at risk. ${ }^{2}$ In India, a dengue virus infection has been frequently encountered in epidemic proportion in several states..$^{3-5}$ It is a notifiable disease, but its exact prevalence is difficult to quantify due to the frequency of epidemics, which appear throughout the country. Primary DENV infections present as, either a nonspecific illness or dengue fever (DF). Secondary infection with a serotype different from that causing primary infection may lead to dengue haemorrhagic fever (DHF) or dengue shock syndrome. ${ }^{6}$

\section{Objective}

To understand the seasonal trend and pattern of disease for timely formulation and implementation of effective dengue control program.

\section{Materials and Methods}

In the present study, blood samples from the clinically suspected cases of Dengue were reviewed for a period of 1.5 years from August 2016 to February 2018. Samples were collected from outpatient department as well as patients admitted in different clinical wards of Pacific College and Hospital Udaipur. It is a tertiary care teaching hospital and provides a full range of medical, surgical and super-specialty facilities. Processing of samples was done at Department of Microbiology, Pacific Medical College and Hospital, Udaipur, Rajasthan, India.

3-5 $\mathrm{ml}$ of blood was collected from each patient by nursing personnel using strict aseptic precautions and serum was collected using standard methods. All the samples were collected after obtaining the informed consent from the patients and contacts. Serum collected was tested for NS1 antigen and IgM/IgG antibodies using one-step immune-chromatographic assay (Dengue Rapid IgM/IgG test and NS1 test by SD BIOLINE) as per the manual provided with the test kit.

\section{Results and Discussion}

From August 2016 to February 2018, a total of 640 blood samples were tested for Dengue. Of the total samples tested, 9.68\% $(n=62)$ were found to be positive for dengue virus. Out of 62 dengue positive cases, 23 $(37.09 \%)$ were NS1 positive, 20(32.25\%) were IgM positive, $17(27.41 \%)$ were $\operatorname{IgG}$ positive and $2(3.2 \%)$ were $\mathrm{IgM} / \mathrm{IgG}$ both positive. As shown in charts -1 


\section{Chart 1: Test wise distribution of positive samples}

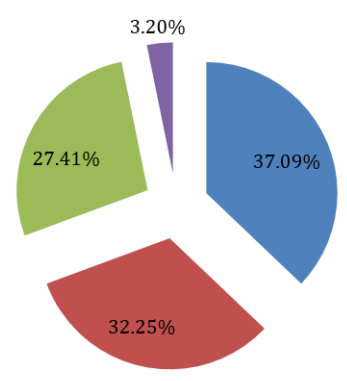

NS1 Antigen

- IgM

$\square$ IgG

IgM \& IgG

From the total 62 positive samples, $38(61.29 \%)$ samples were of male patients and 24(38.70\%) samples were of female patients. So, it was observed that dengue affected males more than females.

In this study, a majority of patients tested positive for dengue cases were of 10-20 years age group $(n=19$, $30.64 \%)$ followed by the age group 20-30 years $(n=15$, $24.19 \%)$ and age group $30-40$ years $(n=12,19.35 \%)$ as shown in table 1 and charts 2

Table 1: Age group wise distribution of positive samples

\begin{tabular}{|l|c|c|}
\hline Age group & $\begin{array}{c}\text { Number of } \\
\text { positive samples }\end{array}$ & Percentage \\
\hline $0-10$ & 2 & $3.22 \%$ \\
\hline $10-20$ & 19 & $30.64 \%$ \\
\hline $20-30$ & 15 & $24.19 \%$ \\
\hline $30-40$ & 12 & $19.35 \%$ \\
\hline $40-50$ & 8 & $12.90 \%$ \\
\hline$>50$ & 6 & $9.67 \%$ \\
\hline & 62 & $100 \%$ \\
\hline
\end{tabular}

Chart 2: Age group wise distribution of positive samples

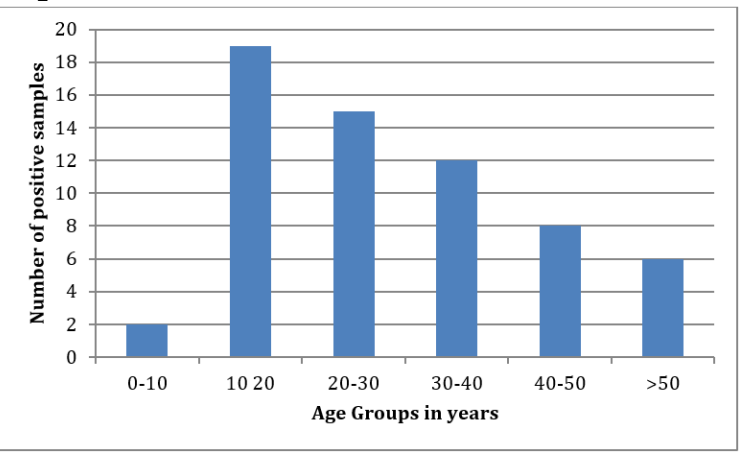

To identify the seasonal variation of the disease, analysis of the data on monthly basis was done. As shown in table 2 and charts 3

Table 2: Month wise distribution of positive samples

\begin{tabular}{|l|c|}
\hline \multicolumn{1}{|c|}{ Month } & No of positive samples \\
\hline August 2016 & 2 \\
\hline September2016 & 3 \\
\hline October2016 & 7 \\
\hline
\end{tabular}

\begin{tabular}{|l|l|}
\hline November2016 & 5 \\
\hline December2016 & 4 \\
\hline January2017 & 2 \\
\hline February2017 & 2 \\
\hline March2017 & 1 \\
\hline April2017 & 1 \\
\hline May2017 & 0 \\
\hline June2017 & 1 \\
\hline July2017 & 2 \\
\hline August 2017 & 3 \\
\hline September2017 & 6 \\
\hline October2017 & 8 \\
\hline November2017 & 7 \\
\hline December2017 & 5 \\
\hline January2018 & 2 \\
\hline February2018 & 1 \\
\hline
\end{tabular}

\section{Chart 3: Month wise distribution of positive samples}

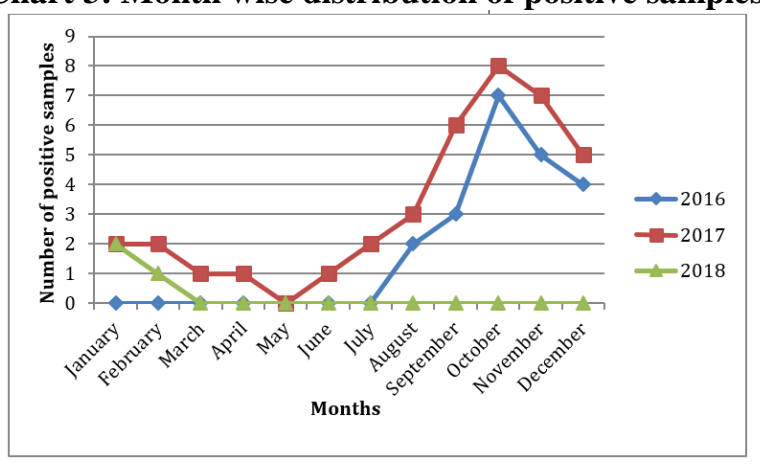

\section{Discussion}

WHO has declared dengue to be hyper endemic in India and cyclical epidemics of dengue are becoming more frequent. Official reported cases of dengue fever are very inadequate. There has been a steady rise in number of dengue cases every year and mortality rate has been going down steadily. ${ }^{7,8}$

\section{Sero-prevalence of dengue infection}

In this study, out of 640 dengue suspected cases, 62 were positive for dengue infection. Out of the total samples tested, $9.68 \%(\mathrm{n}=62)$ were found to be positive for dengue virus. Among 62 dengue positive cases, 23 (37.09\%) were NS1 positive, 20(32.25\%) were IgM positive, $17(27.41 \%)$ were IgG positive and $2(3.2 \%)$ were IgM/IgG both positive. These results are similar to the results observed by Maheshkumar et al in their study in Ajmer. ${ }^{9}$ In another study, done by Sood S, reported $18.99 \%$ seroprevalence of dengue in Rajasthan, India. ${ }^{10}$

\section{Gender-wise distribution}

From the total 62 positive samples, $38(61.29 \%)$ samples were of male patients and 24(38.70\%) samples were of female patients. Our results were similar to the study done by Maheshkumar et al. ${ }^{9}$ Higher seropositivity in males might be because of increased 
exposure at work place or outdoor activities, which results in more exposure to Day biting mosquitoes

\section{Age group-wise distribution}

In this study, a majority of patients tested positive for dengue cases were of 10-20 years age group $(n=19$, $30.64 \%$ ), which includes children and younger adults. This was comparable to the study, done by Deshkar et al. ${ }^{11}$ It is believed to be due to the intrinsically more permeable vascular endothelium and comparatively lower immunity in children rendering them more susceptible to dengue infections. ${ }^{12}$ However, in the study conducted by Neerja $M$ et al, high numbers of cases were seen in the adult age group. This indicates that the virus had been introduced to a non-exposed population. $^{13}$

\section{Seasonal variation}

In the present study, it was found that maximum number of dengue suspected cases were reported in September, October and November. Gunasekaran P et $\mathrm{al}^{14}$ and Deshkar ST et al ${ }^{11}$ have shown similar trends of positivity in their respective studies.

Aedes aegypti has an average adult survival of fifteen days. During the rainy season, survival is longer and therefore the risk of virus transmission is greater. During post monsoon period, stagnant water pool collected during rainy season acts as favourable breeding sites and along with lower temperature during this period, there is an increase in transmission of dengue infection. ${ }^{15,16}$

\section{Conclusion}

Our study concludes that dengue cases are on increase in South Rajasthan. With early diagnosis and treatment, morbidity and mortality can be decreased. This study emphasizes the need for continuous surveillance coupled with vector control program and awareness among the public in combating future epidemics of dengue.

\section{References}

1. Gubler DJ (1998). Dengue and Dengue haemorrhagic fever. Clin. Microbiol. Rev., 11:480-96.

2. R. Ananthnarayan, CK Jayaram Paniker. Textbook of Microbiology.10th Edition, Universities Press (India) Private Limited. 2017:529.

3. Garg A, Garg J, Rao YK, Upadhyay GC, Sakhuja S. Prevalence of dengue among clinically suspected febrile episodes at a teaching hospital in North India. J Infect Dis Immunity.2011;3:85-9.

4. Kalawat U, Sharma kK, Reddy SG. Prevalence of dengue and chickengunya fever and their co-infection. Indian $\mathbf{J}$ Pathol Microbiol.2011;54:844-6.

5. Paramashivan R, Thenmozhi V, Hiriyan J, Dhananjeyan KJ, Tyagi BK, Dash AP. Serological \&entomological investigations of an outbreak of dengue fever in certain rural areas of Kanyakumari, Tamilnadu. Indian J Med Res.2006; 123:697-701.

6. Monath TP. Dengue: The risk to developed and developing countries. Proc Natl Acad Sci USA. 1994;91:2395-400.
7. Dengue: Guidelines for diagnosis, treatment, prevention and control. New edition Geneva: World Health Organization.2009.

8. Shepard DS, Halasa YA, Tyagi BK, Adhish SV, Nandan D, Karthiga KS, et al. Economic and Disease Burden of Dengue illness in India. Am J Trop Med Hyg. 2014; 91(6):1235-42.

9. Maheshkumar, Rohitash Sharma, Geeta Parihar, Mukesh Sharma. Seroprevalence of Dengue in Central Rajasthan. Int J Curr Microbiol App Sci 2015;4(9):933-40.

10. Sood S. A hospital based serosurveillance study of dengue infection in Jaipur (Rajasthan) India. J Clin Diagn Res. 2013; 7(9):1917-20.

11. Smita Deshkar, Sharmila Raut, Ravindra Khadse. Dengue infection in central India: a 5-year study at a tertiary care hospital. Int J Res Med SCI.2017; 5(6):2483-89.

12. Guzman MG, Sierra B, Kouri G, Farrar J, Simmons C. Host and virus determinants of susceptibility and dengue disease. Frontiers in dengue virus research.2010:79-102.

13. Neerja M, Lakshmi V, Teja VD, Umabala $P$ and Subbalakshmi MV. Serodiagnosis of dengue virus infection in patients presenting to a tertiary care hospital. Indian J Med Microbiol 2006; 24:280-2.

14. Gunasekaran P, Kaveri K, Mohana S, Arunagiri K, Suresh Babu BV, Padma Priya P, et al. Dengue disease status in Chennai (2006-2008): A retrospective analysis. Indian J Med Res. 2011;133(3): 322-5.

15. Guidelines for clinical management of dengue fever, dengue haemorrhagic fever, dengue shock syndrome. Delhi: Ministry of Health and Family welfare; 2008. Available at http://www.nvbdcp.gov.in/Doc/ Clinical\% 20guidelines.pdf:

16. Centers for Disease Control and Prevention. Available from http://www.cdc.gov/Dengue

Abbrevations: DHF-dengue haemorrhagic fever, DFDengue fever, RNA- Ribonucleic acid. 